\title{
What are we doing here, anyway? Tying academic library goals to institutional mission
}

n commissioning "The Value of Academic

Libraries: A Comprehensive Research Review and Report" by Megan Oakleaf, ${ }^{1}$ ACRL has issued a professional mandate to academic libraries. ${ }^{2}$ For all of us who have been struggling to keep up with mounting stacks of readings in the field of assessment, Oakleaf's compilation and analysis are welcome. Her report provides context and describes specific techniques for identifying and illuminating the value of an academic library.

The report emphasizes tying the role of the academic library to institutional mission and outcomes by identifying and understanding the parent institution's mission and goals; identifying and understanding how the library contributes to these; and communicating that alignment. ${ }^{2}$

This article expands on ideas for recognizing and elucidating this alignment as preparatory work to developing an assessment plan.

\section{Where are we? Identifying institutional context}

Institutional mission and goals are often clearly publicized on the college or university Web site. Most campuses have readily identifiable mission statements, and they may be long, short, substantive, catchy, enduring, or trendy, and, for your purposes, more useful or less useful. Once you find the institutional mission, don't stop there. In addition to mission and goals, watch for other institutional statements with which you might strategically align, such as:

- strategic plan, strategic objectives;

- vision or values statements;
- college competencies or outcomes; and

- marketing materials.

Although you probably won't find all of these elements, any of them may prove useful in defining the context of the library. For example, my own institution has a mission, vision, strategic plan and goals, values statement, and college competencies, all of which we rely on for direction in setting and assessing library objectives.

Be aware that different institutions may use different terminologies to describe each of these elements. Many institutions aim for succinct mission statements, which may or may not be supplemented by longer, more operational "visions" or "strategic plans," while other institutions value depth and detail over brevity. ${ }^{3}$ You may be able to work effectively with a short institutional mission, but be sure you don't miss a longer articulation under some other name. Similarly, even if the institutional mission statement is substantive, don't discount other elements. My institution has a short vision statement (18 words) and a relatively long mission statement (about 70 words), both of which inform the library's planning and assessment.

In addition to publicly accessible documents, ask key players for ideas. If a new president or chief academic officer joins your institution, pay close attention to any speeches, letters to the community, or other

Janet R. Cottrell is director of academic resources and the library at Champlain College in Burlington, Vermont, e-mail: cottrell@champlain.edu

() 2011 Janet R. Cottrell 
communications. If it suits your institutional culture, request a meeting and explain what you are trying to do, then ask for advice in identifying changes in direction that may tie in with library objectives.

In some cases, institutional statements may be lacking, difficult to find, insubstantial, or otherwise not as useful to the purpose as one might hope. If you encounter that problem, consider looking for similar statements at other levels of the institution. For example, watch for:

- outcomes or goals for the general education curriculum;

- outcomes or goals for specific academic units or programs;

- curriculum proposals;

- goal statements from other areas within the institution, such as recruitment, retention, or engagement goals; and

- research project descriptions; grant funding proposals. ${ }^{4}$

These won't substitute for institutional mandates, but they are excellent supplements and can prove very useful. Working with them will provide practice and experience in the next step: tying the library to broader initiatives within the institution.

\section{What are we doing here? Aligning the library with the institution}

Years ago, academic service units could simply state their aim to support the academic mission of their college or university. Today's climate of accountability and assessment requires a more meaningful connection.

If your library already has a mission, vision statement, objectives, or outcomes, examine them closely for alignment with the institutional materials. Lay them side by side, pin them up around the room, or do whatever works for your team in order to study the library and the institutional materials together.

As you find points of overlap or support, document them: highlight the relevant text and note the overlap in a chart or list. Aim for a literal, visual representation of how the library's work relates to the institution's goals: try to produce a "map" that clearly delineates that alignment. ${ }^{5}$

As you work, watch for any institutional goals the library does not currently support, but could. These may provide important markers to chart your future path, so be sure to include them in your chart or list, even if you have to highlight them in a different color or mark them as "forthcoming."

In some institutions you may find little or no formal library planning or assessment material to compare with the institution's goals. If that is the case, use the institutional elements as a map for library goal-setting. Examine each element to see if you can identify goals, objectives, or values that should be incorporated in the library's own mission and planning materials.

An extreme example of this occurred some years ago when I was asked to write a statement applying the college's institutional mission to the library. At that time the library's mission fell loosely into the "support the academic mission of the college" category - a lack of detail that was inappropriate for the task at hand. The institutional-level statement, on the other hand, articulated many factors that make Champlain College unique, and provided plenty of clues for library alignment. ${ }^{6}$ As I expressed it then, "the challenge was to determine how this vision can best inform the planning and operation of the library. The most expedient approach seemed to be to translate-literally - the college's vision statement by capturing the intent and spirit of it in terms that can be realized in the context of the library." Figure 1 shows the process of "translating" the institutional statement phrase by phrase into language that was relevant for the library.

The resulting library mission statement is long, but it succeeds in capturing the spirit of the institutional statement. ${ }^{8}$ Several years later, during the library's strategic planning process, this particular statement was edited lightly-probably due to its clear and close alliance with the college's mission statement. 
The process of understanding institutional goals and recognizing the library's role in fostering them is not an individual pursuit. Extensive conversations within the library will ensure that all aspects of the library's work are considered, and increase the likelihood of discovering wider connections between the library and the institutional mission - and often lead to a renewed sense of pride and connectedness within the library. These conversations may also help guide future development within the library: elucidating the library's current role in the context of broader institutional goals can facilitate future connectivity simply because it is on people's minds.

\section{How the College's Strategic Vision ...}

"Educate today's students to become skilled practitioners, effective professionals and global citizens"

"Agile"

"Entrepreneurial"

"Blend technology leadership, market savvy, innovation and fiscal responsibility with a commitment to the human touch"”

"This distinctive approach permeates the delivery of relevant, student-centered and rigorous programs in business, applied technology and public service"
= Help educate students to become skilled, effective, responsible information users. That is, people who recognize when they need information, and know how to find, retrieve, evaluate, and use it effectively, efficiently, and ethically.

Able to respond quickly and effectively to fastpaced change in our profession of librarianship and information science, our college, and our higher education arena.

$=\quad$ Undertake the challenge of providing exemplary library and information resources and services in the innovative Champlain College environment; organizing, operating, and assuming the risk for securing and deploying the needed resources in creative, sometimes unconventional ways. As "intrepreneurs," creating and growing an effective library unit within the larger organizational context of the college.

= Secure and deploy the best available technology to support students and faculty in their information needs. Capitalize on the innovative design and purpose of the information commons. Create, maintain, and make known the information commons as an intellectual center on campus that provides a welcoming environment staffed by effective and caring professionals.

= This distinctive approach permeates both the physical and virtual library, its resources, staff, and services, as they provide relevant, patroncentered support to students, faculty, and staff. 
While hardly anyone wants more meetings, time spent on conversations like these may be well spent.

At Champlain College, library folks were actually anxious to talk about our work as part of a bigger picture. Talking about institutional goals proved essential as we developed a library strategic plan and goals. Exploring these connections deepened our sense of engagement and placed our dayto-day work in a broader context. We also found ourselves thinking of that context as we planned future projects. In our planning sessions it is now common for someone to ask "How does that tie in to the college goals?"

\section{Is anybody listening? Communicating the alignment}

Within the library, illuminating the relationship between library and institution helps set the context for everything from day-today tasks to long-range planning and major initiatives. It can inform priority setting and resource allocation, and foster a sense of involvement in the larger endeavor and pride in contributing.

But the resulting alignment is not truly fulfilled until it is communicated outside the library. ${ }^{9}$ As Oakleaf advises regarding information literacy assessment plans, the "connection between [library initiatives such as] information literacy instruction programs and institutional strategic documents is one that is often assumed by librarians but rarely articulated beyond the library organization." 10

Appropriate audiences for this type of communication will vary by institution, and you may choose to target specific audiences by priority or to simply reach as many as possible, including:

- senior institutional administrators;

- other areas within the administration whose goals the library supports, such as enrollment management;

- unit administrators, such as deans or department chairs;
- faculty;

- students;

- prospective students and their parents;

- current and potential donors;

- external recognition or accrediting bodies; and

- granting organizations.

Several formal communication vehicles can be used for this communication, such as:

- annual reports;

- library Web site;

- marketing materials;

- curriculum reviews;

- presentations to faculty or board members;

- library assessment documents; and

- accreditation reports.

Remembering Oakleaf's advice, don't assume that the audience already knows your message. If you mapped the alignment by producing a chart or list illustrating ways that the library supports institutional priorities, include it in your formal communications.

You can also reinforce the notion of alignment informally. When discussing a new idea in library meetings, talk about it in the context of institutional goals and priorities. Do the same in campus meetings and conversations. Share anecdotes about instructional programs or individual student successes in which librarians played a role. Participate in faculty orientations and prospective student visit days, and watch for ways to insert your message.

An exercise that may be helpful is to inventory all the ways you are currently spreading your message of alignment. List all the formal communication mechanisms that you have used, then the informal ones, and then brainstorm any additional venues you might consider. When we attempted a similar exercise in a workshop led by Oakleaf, we realized that we could be using more informal mechanisms. As a result, we are trying to compile faculty and student anecdotes more carefully so that we can work them into our "alignment" communications. 
In both formal and informal communications, practice the art of grace. Getting your message out is crucial, and you may suspect that there is no danger of overdoing it. Generally this is true. But beware of the possibility of boring your audiences through repetition. Most of us share an aversion to overly persistent sales pitches. If you feel as though you are simply repeating yourself, examine your message to see whether you can tailor it more specifically to the values and goals of each audience, and monitor those values and goal for change over time.

\section{Where do we go from here?}

The preparatory steps described here for identifying and understanding the parent institution's mission and goals, determining their overlap with the library, and communicating that alignment can help to set the stage for more authentic assessment of academic libraries.

Of course, these steps alone are not sufficient. For most of us, the hard work of documenting the value of the library has yet to be done. Addressing any one of the potential areas of library impact detailed in the "Research Agenda" section of "The Value of Academic Libraries" report ${ }^{11}$ requires an ongoing commitment of time and effort. But the exercise of examining in detail the alignment between the goals of the library and those of the institution provides a strong foundation for that work. In the process, a growing recognition of the strength of that alignment —and perhaps the discovery of opportunities for new connections-may renew our sense of purpose and strengthen our determination for the task at hand.

\section{Notes}

1. ACRL, "The Value of Academic Libraries: A Comprehensive Research Review and Report, "researched by Megan Oakleaf, www. ala.org/ala/mgrps/divs/acrl/issues/value /val_report.pdf (accessed June 20, 2011).

2. Ibid., 29-30.

3. Kevin Kiley, "Saying More with Less," Inside Higher Ed., www.insidehighered.com /news/2011/06/20/colleges_pare_down _mission_statements_to_stand_out (accessed June 20, 2011).

4. See also ACRL, "The Value of Academic Libraries," $94 f f$ for additional ideas.

5. For an excellent discussion and sample of a "mission impact map," see Table 2 and text on p. 68 of Megan Oakleaf's "Are They Learning? Are We? Learning Outcomes and the Academic Library," Library Quarterly 81 (2011), www.jstor.org/stable/10.1086/657444 (accessed July 25, 2011).

6. Champlain College, "Mission Statement and Values," www.champlain.edu /About-Champlain/Mission-and-Values.html (accessed July 5, 2011). The mission statement reads: "Champlain College endeavors to be a leader in educating today's students to become skilled practitioners, effective professionals and engaged global citizens. Champlain's agile and entrepreneurial approach to higher education uniquely blends technology leadership, market savvy, innovation and fiscal responsibility with a commitment to liberal learning, community involvement and 'the human touch.' This distinctive approach permeates the delivery of relevant, rigorous student-centered programs in business, arts, applied technology, and public service."

7. Champlain College, Champlain College Library Annual Report, 3-4. cosmos.champlain.edu/library/pages/about _library/20052006AnnualReport.pdf (accessed July 21, 2011).

8. Champlain College Library Vision Statement, http://cosmos.champlain.edu/library /pages/about_library/vision.html (accessed July 5, 2011).

9. ACRL, "The Value of Academic Libraries," 30 .

10 Megan Oakleaf, "Writing Information Literacy Assessment Plans," Communications in Information Literacy 3 (2009), 82, http://search.ebscohost.com/login.asp $\mathrm{x}$ ? direct $=$ true $\& \mathrm{db}=$ lih $\& \mathrm{AN}=52241846$ \&site =ehost-live (accessed July 1, 2011).

11. ACRL, "The Value of Academic Libraries," 101-39. n 